\title{
ASSESSMENT AND SELECTION OF MATERIALS FOR MELBOURNE CITY COUNCIL HOUSE 2
}

Dominique Hes, Andrew Walker Morrison and Margaret Bates (RMIT University)

\section{ABSTRACT}

This paper highlights the role of material selection in the development and contribution toward environmental excellence in the building project Council House $2\left(\mathrm{CH}_{2}\right)$. The paper focuses on the assessment of material and the strategies used by the design team in $\mathrm{CH}_{2}$ to ensure the best environmental result. The paper then goes on to explore in a case study the application of these strategies in the selection and specification of concrete on $\mathrm{CH}_{2}$. The purpose of the paper is to explore the difficulties and rewards of careful research of manufacturers' claims and the relative benefits of different materials. The paper concludes that the process of material selection adopted on this project has increased the education of architects and manufacturers alike as well as being environmentally beneficial.

Keywords: material selection, concrete, specification, embodied energy.

\section{INTRODUCTION}

Buildings account for one-sixth of the world's fresh water withdrawals, one-quarter of its wood harvest, and two-fifths of its material and energy flows... Building and construction activities worldwide consume 3 billion tons of raw materials each year or 40 percent of total global use. (Roodman and Lenssen, 1995)

As buildings become more energy efficient and other impacts become offset through improvements in design and application, the role and impact of materials becomes more important particularly over the life of a building. This paper looks at the role of materials selection and the current methods of assessing the environmental impacts of materials. The progression of materials through the $\mathrm{CH}_{2}$ design phase is looked at to show the ways in which the issues and challenges of materials selection can play out in reality and be resolved (to some extent). Concrete is then used as an example in the case study to look at the decision making process used in the $\mathrm{CH}_{2}$ project; the influences on decisions and the outcomes.

It has been generally held that operational energy requirements are by far the greatest environmental impact over a project's life, with operational energy overtaking the energy it takes to make a standard commercial building in as little as five to ten years. But as Roodman and Lenssen (1995) indicate, the reality is that such figures do not tell the whole story. Particularly as buildings become more operationally efficient the relative environmental impact of building materials will be greater again. However, materials have impacts other than only energy. These include:

- Habitat degradation arising from logging, mining, transport, waste dumping and pollution from various stages of extraction, production and disposal.
- Erosion of natural capital through (short) one-life use of most materials

- Greenhouse gas emissions from transportation, production, installation and demolition/disposal.

- The construction industry constitutes a large percentage of total economic activity in most countries. Therefore there is nonconstruction impacts in other areas of the economy driven by the practices used in the construction industry, for example waste.

As a result $\mathrm{CH}_{2}$ sought to establish new benchmarks in the selection and use of 'sustainable' building materials in its construction.

Most of the in-depth research on materials has been done on individual materials - e.g. steel, timber. Published studies looking at the contribution of all materials tend to focus on embodied energy. Embodied energy (EE) looks at the total non-renewable energy used to create a product or material from cradle to cradle, the Australian Greenhouse Office (AGO, 1999, p.98) define it as: 'the energy required directly and indirectly to manufacture a product.' Within this there can be considerable range. One study found that $E E$ per $m_{2}$ of floor area of buildings can be between $4-12 \mathrm{GJ} / \mathrm{m}^{2}$ - representing less than $5 \%$ of the total energy consumption of the building investigated (Cole 1998; Cole and Kernan 1996). Another study shows $7 \mathrm{GJ} / \mathrm{m}^{2}$ (Scheuer et al., 2003) for a six storey university building with a life span of 75 years $(2.2 \%$ of life cycle primary energy consumption), while in Japan looking at a 40 year life span the materials and construction component was $8.95 \mathrm{GJ} / \mathrm{m}^{2}-15 \%$ of total energy (Suzuki and Oka, 1998). Large though these numbers are, they all represent a small percentage of the total energy consumed by the building over its life. The exact percentage of capital and churn EE relative to operational energy has been disputed and therefore it is possible that EE could vary between 4 and 40 years of operational energy. More research is needed in this area.

The Organisation for Economic Co-operation and Development (OECD) reported in 2002 and 2003 that buildings consume $30 \%$ of available raw materials, $42 \%$ of energy, generate $40 \%$ of our emissions to air and $40 \%$ of waste to landfill (OECD, 2002; 2003). In Australia, the built environment also accounts for around $12 \%$ of our consumption of potable water (ABS, 2000). Further, the materials in buildings can significantly affect human health. The indoor air level of many pollutants, the OECD reported, may be 2.5 to 100 times higher than outdoor levels. The indoor air level of pollutants is primarily emissions from the fitout materials and some building materials.

The focus for material selection should be on the choice of materials, using the traditional design paradigm of reduce - reuse - recycle, aiming for healthy indoor air, resource conservation and the minimization of waste and emissions. These will be briefly discussed after a general introduction to the complexity of assessing material environmental performance. 


\section{General techniques for assessing materials}

There are many guidelines and techniques used internationally to assess materials for their environmental credentials (Berge, 2001; Woolley and Kimmins, 2000; Anderson et al., 2002; Curwell, 2002), however there is no specific overall standard. One of the most rigorous methods is life cycle assessment (LCA), a method for assessing impacts of a product over its life including all of its measurable inputs and outputs. However, there are several problems with LCA. The first is with the reliability and extent of data collected for the databases on which the assessments are based. Studies on materials are either relatively accurate and take a lot of time, resources and are often confidential, or they are more generic and less accurate. A second and related problem is the amount of time and the cost of carrying out LCAs which is beyond most building projects. A third problem is that while LCA is strong at estimating readily quantifiable materials flows such as in a manufacturing process, there are important impacts that LCA does not include, typically biodiversity loss and habitat degradation. Generally manufacturers are the ones who take on the expense of an LCA to try to make their product stand out and improve their production processes.

Because of these complexities projects often turn to simpler indicators such as embodied energy, material intensity per service unit (MIPS) ${ }^{1}$ or footprints (total land used to produce a product). But these indicators tend to consider only one or a limited set of indicators, such as energy and land used, whilst ignoring possible other crucial impacts such as toxicity. Embodied energy figures are also typically based on capital accounts that include all of the costs associated with a product and allocate an energy conversion factor. This does not reflect actual energy used to make the product and is often very large as it can include the relative cost of financing the transport company carrying the product and so forth. On the other hand using embodied energy based on national accounts does simplify the process of collecting the information because there is financial data readily available on all products and processes.

Another method of simplifying the LCA type process is through aggregation tools which are based on LCA but provide results in simple aggregated scores. Examples of aggregation tools are the European Ecolndicator used in EcoQuantum (housing environmental and costing tool), and EcolT (material selection of industrial design), cost (first and future costs) and BEES which assesses environmental impacts. The main problem with these types of tools is that the data behind them is often hidden and it is difficult to add new data if the product being considered is not listed. The lack of uptake of these aggregation type tools is highlighted by the fact that there have been no updates on BEES since late in 2003. Yet another simplified method to support decision making on material selection is through labelling. There is no internationally successful program on construction material labelling though there have been several attempts. The main problem with labelling construction materials is the variance of these materials from location to location. Greater success has been achieved through specification or material choice support tools such as EcoSpecifier and the US Environmental Building News, and guidelines such as the Aurora Material Selection Guideline and the US Federal Government's environmentally preferable purchasing (EPP) database. The US Federal Government defines an environmentally preferable product as:
... goods that have a lesser or reduced effect on human health and the environment when compared to competing products that serve the same purpose. Environmentally preferable attributes include reduced toxicity, the use of recycled materials, and increased energy efficiency. (US Environmental Protection Agency, 2004)

Labelling is almost always done by a third party that is independent from the manufacturers or their professional organisations, often including some kind of certification. For example the Forest Stewardship Council certifies the certifiers (SmartWood and Scientific Certification Systems) that assess whether forestry companies are using sustainable management practices to harvest wood. In the USA, GreenGuard certifies products that meet strict indoor air quality criteria. The Energy Star label is an international standard which identifies equipment and appliances that meet or exceed standards for energy efficiency, and now there is the water 'A-rating' label indicating water efficiency (Global Green, no date). In Australia there is an overall building rating called Green Star, created and implemented by the Green Building Council of Australia. However, the place of materials in the rating system is integrated into the point system rather than having a separate section

\section{$\mathrm{CH}_{2}$ SELECTION AND DESIGN STRATEGIES}

\section{The brief}

Melbourne City Council's Brief for $\mathrm{CH}_{2}$ stated that:

The building is to be a lighthouse for future City developments;

- It is to provide a comfortable, adaptable and stimulating working environment for its users, the staff of Melbourne City Council;

- It is to be seen and understood to respond to its natural as well as its social environment and to make use of resources bearing in mind the efficient use of embodied energy both in the choice of materials and in the process of their use;

- It should maximize the use of renewable energy within the bounds of present technology by harvesting sunlight, the wind and rainwater together with the complexities of the Melbourne climate and by following these principles the building should reduce $\mathrm{CO}_{2}$ emissions to almost zero;

- It should also provide at least the same area of green cover as its footprint bearing in mind that this area can be measured vertically as well as horizontally; and

- Finally as a work of art the building should inspire a new relationship between the city and nature.

An outcome of this was the development of a 'comprehensive materials assessment process' that aimed to consider key environmental aspects of a material but with three overarching priorities:

- Use and adherence to the principle of lowest life-cycle cost for the anticipated 100 year life i.e. maximizing durability, minimizing replacement, maximizing maintainability

- Minimizing embodied energy

- The use of locally grown, sourced or manufactured products and materials.

\footnotetext{
1 MIPS quantify the material intensity of a product or service by adding up the overall material input which humans move or extract to make that product or provide that service. It puts life cycle thinking at the beginning of the product chain. MIPS is measured in kilogram per unit of service. The material input is calculated in five categories: abiotic raw materials, biotic raw materials, water, erosion and air.
} 
The central role of materials from the charrette stage A comprehensive materials assessment process was first explicitly addressed from the two week-long design charrette. The architectural design process typically starts from preliminary or 'Schematic Design', literally the schema or rough placement of spaces and shapes, through to design development, where buildings are typically drawn to scale and resolved in some detail, to contract documentation, which involves the documentation of the project in all respects to allow its construction. Materials selection, even in 'green' projects, is often considered at the stage of design development - or even contract documentation. A combination of aesthetic/functional/cost drivers and the designers' familiarity with broadly available products drives implicit and explicit decisions: 'I know we can do this in brick, this in steel, this in timber.' The exact specification is typically resolved near the end of the projects life in the designers' office.

However this 'business as usual' process can carry a high cost that can limit ecologically sustainable development (ESD) to the ecological impacts of individual building materials. For example it is common industry practice to use plasterboard or fibre-cement sheet wall lining in most buildings. This practice allows cables, pipes and services to be routed over the building structure but hidden by the wall and ceiling finishes. However it can eliminate opportunities to use the effective thermal mass of a concrete structure. A completely different design of services and construction is required for a concrete structure as the finish. This is not something readily done after schematic design. It also fails to consider the life-cycle impacts of these lining substrates and a raft of practices implicit in their use, such as replacement and repainting of surfaces that are ultimately easily marked and abraded.

\section{Step 1: Synergy, honesty and simplicity in materials}

In the initial charrette the design team put up a proposal for discussion and constructive criticism that used a concrete structure and extensive thermal mass and pursued synergy, honesty and simplicity in materials use.

- Synergy: obtain multiple benefits from a materials use e.g. use the structure as a thermal mass and durable finished surface.

- Honesty: use materials for their aesthetic and other intrinsic properties, seek not to clad, coat or hide them.

- Simplicity: simple is better than complex. Monolithic materials are easier to maintain, repair, and recycle than laminated, glued, composite products.

This approach, according to Designinc, strongly influenced from the outset the design team's philosophy and aesthetic that was likely to be radically different from many contemporary 'Grade $A^{\prime}$ commercial buildings. It would be the genesis of innovative thinking that resulted in the striking selection of materials and finishes throughout the project.

\section{Step 2: A planned approach to materials research and specification}

The consideration of specific materials did not come up in the initial charrette: only that whatever materials were selected had to be in keeping with the design philosophy, and adhere to the requirements of the brief including minimizing embodied energy, life-cycle costs, and general environmental preferability.

The next question was how to achieve this in practice. In 1999 there were very few tools available to the design team to aid their research. EcoSpecifier was in its earliest days of development and had only 80 products listed. There were no other local resources available. Designinc was left with only one option - to undertake the enormous research task of vetting all potential products and materials that might be used on the project.

A rolling $R \& D$ program was designed, commencing in 2000 . The key elements of this program were:

- Establish a methodology for side-by-side comparison of products through the Environmental Performance Questionnaire (EPQ), discussed below.

- Establish a peer-review process to ensure transparency and accountability, and limit liability, through the involvement of the Commonwealth Scientific and Industrial Research Organisation (CSIRO).

- Shortlist potential products and issue the questionnaire as a condition of consideration to suppliers for completion, and to other suppliers through the course of the project as relevant.

- Establish in-house systems that would enable effective storage, referencing and use of data through effective storage and interpersonal communication.

- Integrate data into effective decision-making in the project in a timely manner through coordination and project reviews.

Designlnc used a slightly modified Environment Australia 'Environmental Performance Data Sheet' as their 'Environmental Performance Questionnaire' or 'EPQ' to generate standardized responses from suppliers. Questions asked by the EPDS/ EPQ include:

- The type and relative contributions of different materials in the product

- The energy required to make the product in its various manufacturing stages, and the energy source.

- Whether the product contains or during production emits any of a list of chemicals listed by the Australian National Pollutant Inventory.

- The projected lifespan and ability to repair the product.

These responses were provisionally reviewed before being forwarded to the CSIRO for scoring. The CSIRO team was asked to develop a scoring system and, from the responses to the EPQ, give each product a final score.

The CSIRO method was as follows:

Step 1 - The material assessment was carried out on (1) product-manufacturer or product-supplier responses to a set of questionnaires on product composition and manufacturing, and (2) considered opinions of CSIRO experts. Neither of these on its own was considered to be sufficient to calculate the ratings.

Step 2 - The comparative ratings of products within each category/ application were used as an initial guide to product selection to narrow the options for a specific project application. The ratings were not used as a substitute for more detailed investigation by the project team and expert consultants and/or specific testing of product attributes by experts, which may still be required in some cases in making a final selection. 
Step 3 - The ratings were made by expert input and qualitative information where available within each category/ application for each product property or attribute under a specific context of use (considered a 'standard' condition). For different conditions and context of use it was acknowledged that performance might vary. Thus ratings were comparable only within categories/applications. The table was meant as an initial guide for quick comparisons of product attributes across a range of areas.

Step 4 - The products were not categorised as either bad or good; that is, a single composite rating was not given. A range of important attributes for sustainable performance (i.e. 'friendly' to people and environment) were considered. Project clients and design team were encouraged to consider the relative importance of each attribute in a particular project in their comparisons and selections (i.e. the sense of relative importance of each attribute for each product category may vary from project to project).

Step 5 - Where appropriate, good performance was identified/ noted. Where the rating for a product attribute was not satisfactory, the intent was to note it to encourage improvement in this area.

An example of a product scoring sheet is given in Table 1

\section{Evergen - Product Selection Guide}

Legend: 4 Superior; 3 Good; 2 Average; 1 Poor; 0 Not acceptable; - Insufficient information

\begin{tabular}{|c|c|c|c|c|c|c|c|c|c|c|c|c|}
\hline \multirow{2}{*}{$\begin{array}{l}\text { Category/ } \\
\text { Application }\end{array}$} & \multirow{2}{*}{$\begin{array}{l}\text { EPQ } \\
\text { Ref. } \\
\text { No. }\end{array}$} & \multicolumn{8}{|c|}{ Attributes } & \multirow{2}{*}{$\begin{array}{c}\$ \\
\text { Range }\end{array}$} & \multirow{2}{*}{$\begin{array}{l}\text { Aust. } \\
\text { Made } \\
\text { (Y/N) }\end{array}$} & \multirow[t]{2}{*}{ Comments } \\
\hline & & $\mathrm{EE}$ & $\begin{array}{l}\text { Emb. } \\
\text { water }\end{array}$ & $\begin{array}{l}\text { Wastes \& } \\
\text { Recycling }\end{array}$ & $\begin{array}{l}\text { Air, Land } \\
\& \text { water } \\
\text { emissions }\end{array}$ & $\begin{array}{l}\text { Indoor } \\
\text { Emissions }\end{array}$ & $\begin{array}{l}\text { Other } \\
\text { Env } \\
\text { impact }\end{array}$ & $\begin{array}{l}\text { Service Life } \\
\text { (without } \\
\text { maintenance) }\end{array}$ & $\begin{array}{l}\text { Maintenance } \\
\text { Requirement }\end{array}$ & & & \\
\hline Glazing & GL.xx.xx & 3 & 1 & 3 & 2 & 3 & 2 & 2 & 4 & & & \\
\hline
\end{tabular}

Table 1: Example score sheet (used with permission from CSIRO)

\section{CHALLENGES IN IMPLEMENTATION}

\section{Gathering data}

The first challenge was getting manufacturers and suppliers to fill in the questionnaires. Despite the fact that completion of the EPQ was a condition of consideration, at $25+$ pages, and designed to assist life-cycle assessments, the questionnaires were highly technical and beyond the experience of many who received them. About $50 \%$ of suppliers did not respond. Only about $30 \%$ of all $E P Q s$ issued or requested were fully completed.

To address this problem later in the project, towards the selection of fitout materials, Designlnc designed and issued a simplified three-page EPQ. Up to $80 \%$ of suppliers returned the document completed. Designinc's Claude Bertoni notes that another factor in this may be that a) the project was better known and b) that over the period of design the supply sector in Australia had improved significantly with regards to $\mathrm{ESD}^{2}$.

While there was a product ESD-claim declaration sign-off as part of the form, there were concerns about the quality of the data given, as highlighted by Bertoni: "My major fear has been relying on a manufacturer's word. I would put at the top of my wish list independent accreditation of products to give peace of mind. ${ }^{3}$

Ultimately it was CSIRO that had to make sense of complete, partial, or contradictory data and supply project recommendations. Principal Research Scientist, team leader EVERGEN, CSIRO, Greg Foliente, comments on how this issue was resolved:
When a manufacturer is not capable of answering those questions, it shows their environmental credentials. We shouldn't water it down, because it would break the process. Secondly, even though some of the questions are not filled in, we ... are relying on expert opinion. Once we know the raw materials and what the product is, we can guess what goes in between. It's inexact, but we know enough about the industry. Give us a few parameters here and there, and we develop a feel. Then the experts come in with the rest. As long as we are consistent, the idea is that they are always rated next to each other, and as long as you have that, it is okay.

... we wanted to preserve the integrity of the RMIT effort. Also we knew [the EPQ] wouldn't be sufficient anyway. So the idea was to use it as base information. Then we relied on the expert judgement of people in CSIRO who are familiar with the issues... This is an informal process we adopted within the EVERGEN team. ${ }^{4}$

On-site substitution

Substitution during construction of non-specified products is a problem endemic to the construction industry. Over the years various contractual clauses have been developed to limit this, including clauses such as 'Taps to be (x) or similar approved', where approval is by the architect or other person nominated. All approaches however are far from ideal. The designer's control is largely eliminated in many contracts where the project is passed over to the builder. In many other instances sub-contractors will simply use non-specified materials, hoping to get away with it on the project.

\footnotetext{
${ }^{2}$ Conversation with Claude Bertoni 24/01/2005.

${ }^{3}$ lbid.

${ }^{4}$ Interview with Greg Foliente...9 June 2004.
} 
Designinc proposed a strategy to avoid this problem:

i. The builder's Environmental Management Plan was to contain provisions requiring that no substitution was permitted unless the proposed product had undergone independent vetting using the EPQ and subsequent vetting, and was shown to be equivalent to the originally specified product. The architects would have 10 days on receipt of such documentary proof to permit the substitution.

ii. That if the architects rejected the proposed substitution no impact on the program would be permitted. The onus was on the builder to not put up substitutions unnecessarily, and if it was not approved any lost time through delay or scheduling was their responsibility. This created great incentive for the builder to thoroughly assess all products well ahead of time as any problems during the project caused by products they were not familiar with and delayed the project would be on their head.

iii. The builder deposits a $2.5 \%$ bank guarantee as security against making good required by the architect due to non-permitted substitutions.

In the end, points (i) and (ii) were included in the contract. Point (iii) was considered too onerous during contract negotiation and was not included.

\section{The influence of 'Green Star'}

The introduction and launch of Green Star in 2003 marked the start of a whole new learning curve for the project team. Having substantially designed the project, they now had to ensure that it would meet the highest levels established by the Australian Green Building Council's new rating tool. Green Star attributes a relatively modest $15 \%$ of available credits for the base building materials, and there is no doubt that tool focused the broad attention of the project team to meeting the particular relevant requirements: reducing PVC use, avoiding the use of rainforest and old-growth timber; using recycled content in concrete and steel, etc. Table 2 identifies the Green Star credit and the actions taken to ensure $\mathrm{CH}_{2}$ complied so far as was possible.

\begin{tabular}{|l|l|}
\hline Green Star Credit & $\mathrm{CH}_{2}$ Response \\
\hline $\begin{array}{l}\text { Up to } 2 \text { credits for use of post-consumer recycled } \\
\text { steel }\end{array}$ & $\begin{array}{l}\text { Use of } 100 \% \text { post-consumer reinforcement steel from Smorgon Steel. No other } \\
\text { recycled steel products could be identified for the project. }\end{array}$ \\
\hline $\begin{array}{l}\text { Up to } 3 \text { credits for use of high-supplementary } \\
\text { content (cement replacements) in concrete }\end{array}$ & $\begin{array}{l}\text { Development of matrix with up to } 60 \% \text { replacement depending on stress } \\
\text { grading and curing speed constraints. Refer Case Study. }\end{array}$ \\
\hline Up to 2 credits for use of sustainable timber & $\begin{array}{l}\text { Use of plantation timber products. Use of recycled timber for louvres. Use } \\
\text { of FSC-certified timber. Use of responsibly sourced timber with source } \\
\text { documentation for window frames }\end{array}$ \\
\hline Up to 2 credits for reduced use of PVC & $\begin{array}{l}\text { Use of HDPE for most water and other pipework. PVC used for stormwater } \\
\text { pipes. PVC used for power, data and communication cables. }\end{array}$ \\
\hline
\end{tabular}

${ }^{*}$ A contentious product that generated significant debate during the project's construction.

Table 2: Green Star - Office Design (v1) and $\mathrm{CH}_{2}$ materials

\section{ESD priorities at $\mathrm{CH}_{2}$}

Within this assessment the following issues were specifically looked at, for particular material categories:

\section{Minimizing indoor air pollutants by specifying:}

- Low VOC paints.

- Low VOC carpets.

- Low VOC adhesives and sealants.

- All composite wood product is low emission formaldehyde.

Recycled content of structural concrete:

All efforts were made to maximize the use of recycled content in the structural concrete elements. Being mainly pre-cast the challenge was to work with the suppliers to achieve the aim of recycled concrete aggregate and replacement of cement with industrial waste such as fly ash and slag. The structural engineers, Nat Bonacci and Roger Sykes from Bonacci Group, were interviewed on this issue. They commented that such a target was useful but they needed to work with manufacturers to ensure the other requirements such as strength, appearance, etc. were met. They also said that they would achieve the overall target but that some elements would have more recycled content while others would have less depending on their functional requirements. ${ }^{5}$

\section{Recycled content of structural steel:}

The Green Star process highlighted the difficulty of gaining information necessary when making key decisions on materials. To meet the project requirements of one Green Star credit point, recycled steel had to be sourced. No guarantee from local steel manufacturers could be given that $30 \%$ recycled content could be achieved. To meet this then the project team needed to look outside Australia to get the recycled content which allowed the achievement of this one star. The steel is being imported from Thailand. 


\section{PVC minimization:}

All effort was made to minimize PVC which has a high off-gassing component and is not readily recyclable. This has been achieved for all hydraulics and for the data and power cabling.

\section{Sustainable timber selection:}

Over $90 \%$ of the timber used on the project will be from recycled or certified sources. The main issue with achieving this score was the transparency and validity of certification processes. Some certification schemes due to the recent introduction to the market are not as well received or supported by stakeholders as others.

\section{CASE STUDY: CONCRETE AT $\mathrm{CH}_{2}$}

Concrete is a ubiquitous material in construction, offering strength versatility, and durability at a relatively cost effective price.

It is also highly energy and greenhouse gas intensive. The production of one tonne of concrete typically uses cement with an associated environmental price of one tonne of $\mathrm{CO}_{2}$. Figure 1 illustrates the emissions impacts of a tonne of concrete made using entirely ordinary Portland cement (OPC) through to various fuel mixes and substitution of OPC with recycled extenders such as blast furnace slag and fly-ash.

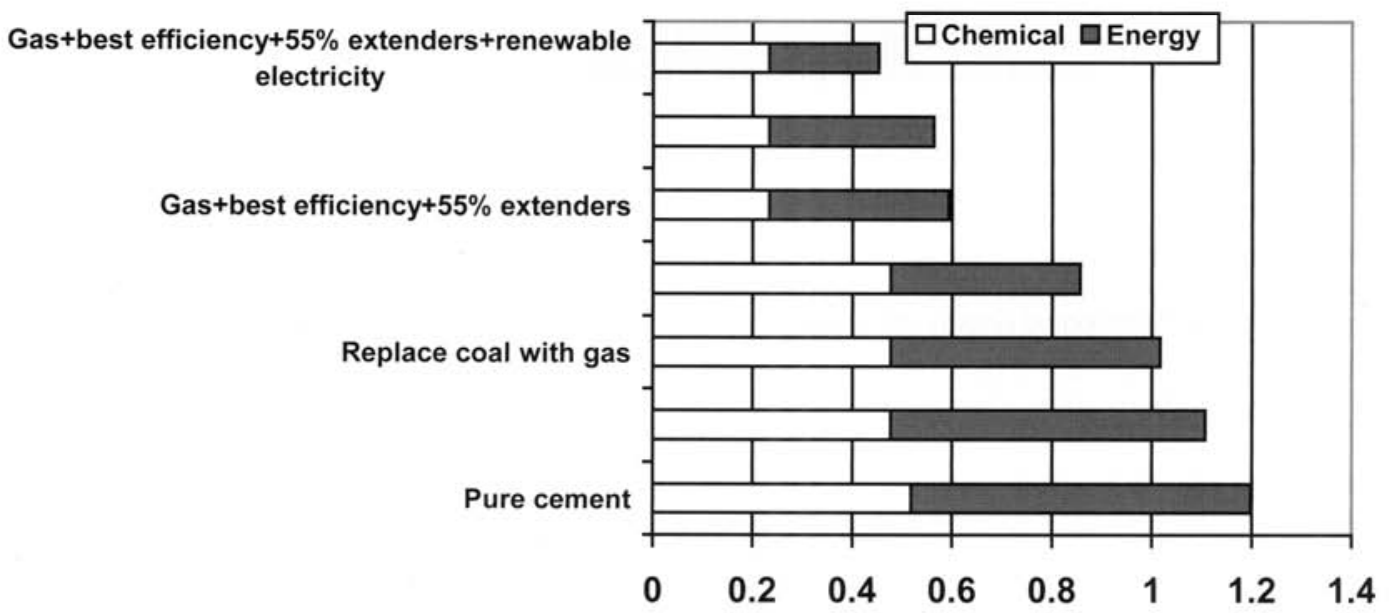

Tonnes of $\mathrm{CO}_{2}$ /tonne of cement product

Figure 1: Chemical and energy $\mathrm{CO}_{2}$ emissions from cement production under various conditions (Pears, 2000)

As can be seen from Figure 1, greater than $50 \%$ reductions in emissions can be achieved through the use of gas-fired dry-process cement with the use of recycled extender or 'supplementary' products. The total embodied energy of reinforced concrete can be further reduced through the use of post-consumer recycled steel reinforcement from an electric arc furnace (EAF) process such as used by Smorgon Steel. EAF mills are inherently up to $70+\%$ more efficient that blast-furnace mills, however they can only process existing steel ingot or recycled steel.

Concrete, due to its use in significant quantities in many commercial buildings, can contribute a significant percentage of the base buildings overall embodied energy. While a detailed LCA or embodied energy analysis of $\mathrm{CH}_{2}$ has not been undertaken, the 2000 Melbourne 'Build LCA' study looked in detail at a range of buildings including two small offices as well as other building types. The results for Office $1\left(6,500 \mathrm{~m}^{2}\right)$ are shown in Figure 2 and the results for Office $2\left(27,350 \mathrm{~m}^{2}\right)$ are shown in Figure 3 . The results are shown by material for these buildings.
As can be seen, concrete was found to be the second largest single energy input into the buildings, at 2.0 and $2.2 \mathrm{GJ} / \mathrm{m}^{2}$ respectively. This represents approximately $20 \%$ of the total embodied energy. $\mathrm{CH}_{2}$, at $12,500 \mathrm{~m}^{2}$ gross floor area, contains approximately 5,200 tonnes of concrete (not including mass of steel reinforcement). On the basis of a business-as-usual worst case this equates to approximately 5,200 tonnes of $\mathrm{CO}_{2}$ - in broad numbers equivalent to the emissions of 12,500 family cars travelling the Australian average of $15,000 \mathrm{~km}$ each over a year.

The $\mathrm{CH}_{2}$ design team was looking to reduce the embodied energy as much as possible. However the project's stated intention to achieve six stars under Green Star meant that every credit point mattered. The team now had an implicit energy 'budget' to attain.

The points related to recycled content in structural concrete are shown in Table 3. 


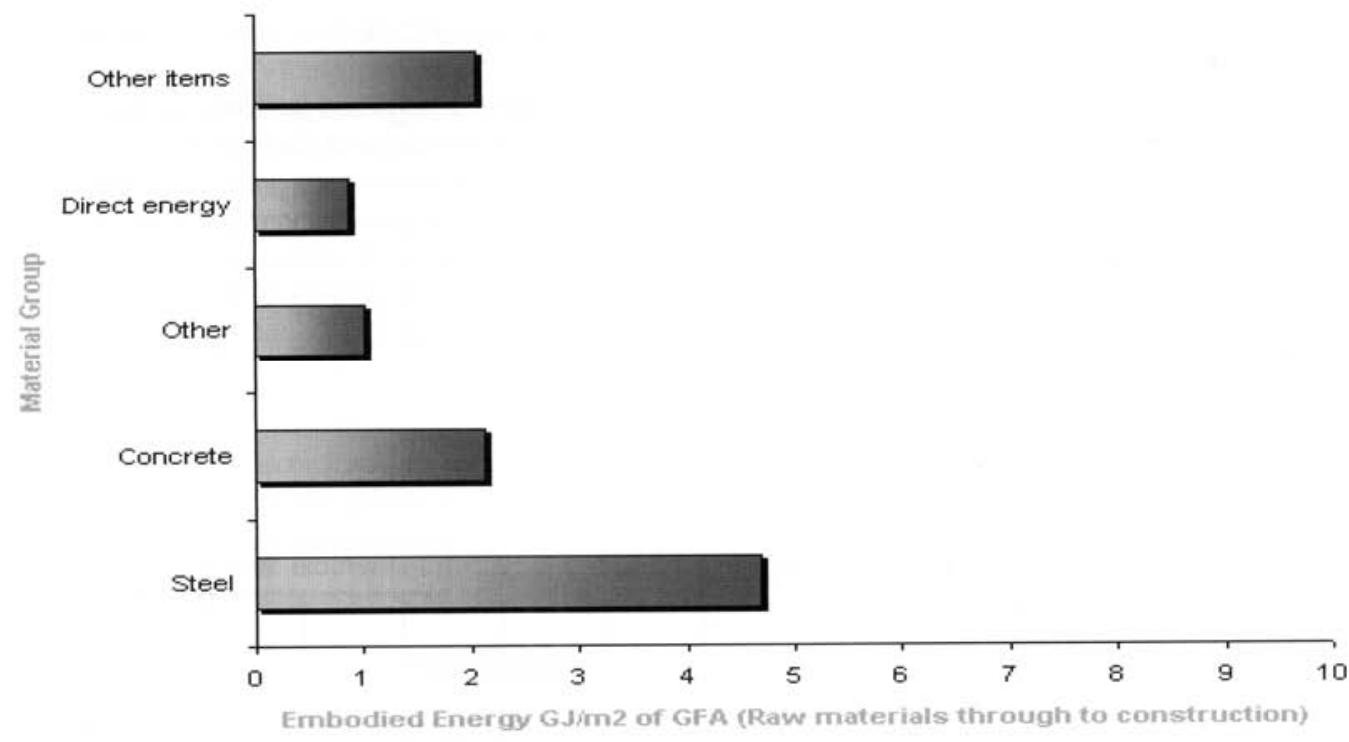

Figure 2: Small Office 1 Embodied Energy (Input/Output type analysis) 6,500m² GFA (Greening the Building Life Cycle, 2000)

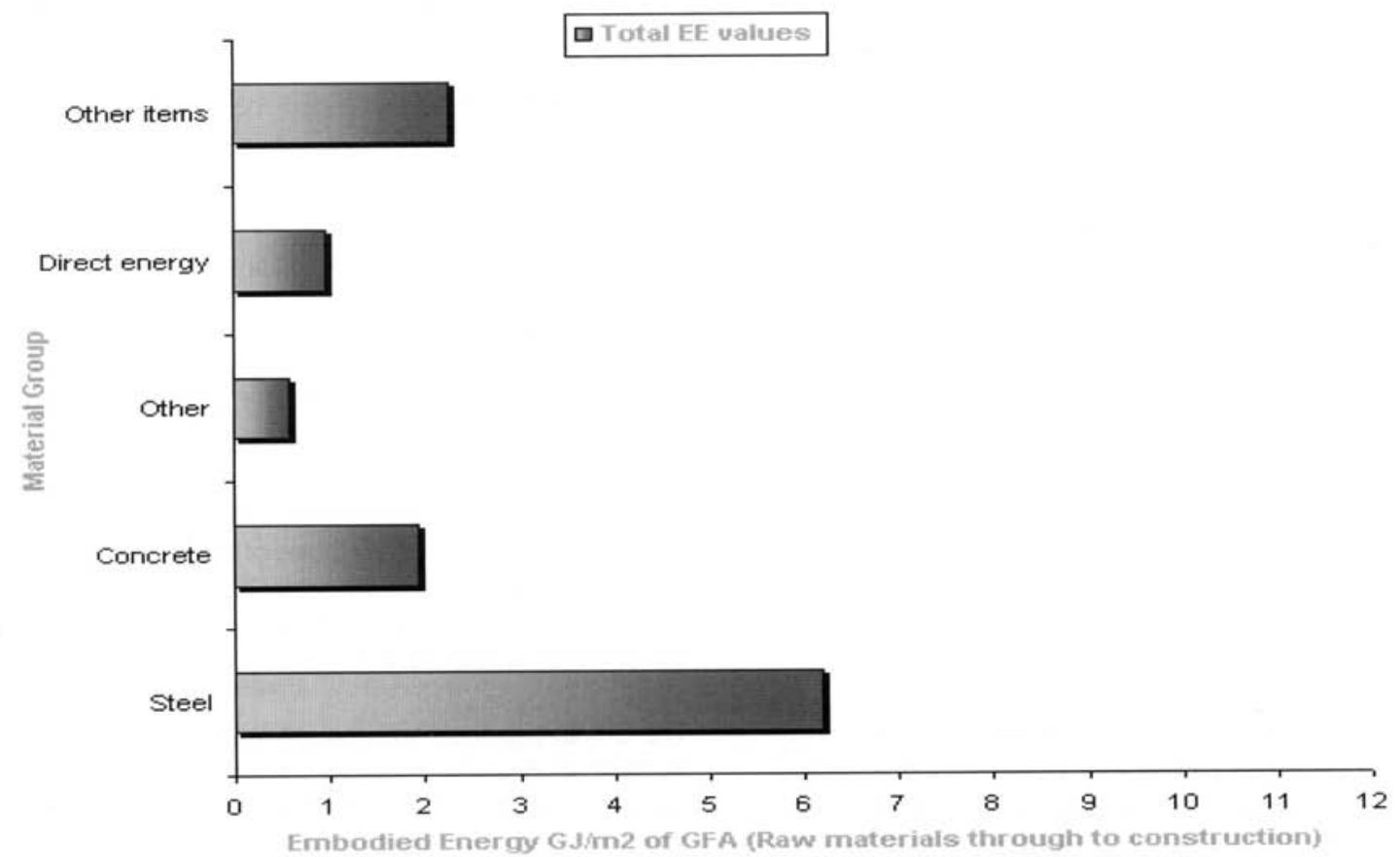

Figure 3: Small Office 2 Embodied Energy (Input/Output type analysis) 27,350m² GFA (Greening the Building Life Cycle, 2000) 


\begin{tabular}{|c|c|c|c|}
\hline TITLE & AIM & CREDIT CRITERIA SUMMARY & $\begin{array}{l}\text { CREDITS } \\
\text { AVAILABLE }\end{array}$ \\
\hline $\begin{array}{l}\text { Recycled Content of } \\
\text { Structural Concrete }\end{array}$ & $\begin{array}{l}\text { To reduce embodied } \\
\text { energy and resource } \\
\text { depletion due to use } \\
\text { of concrete. }\end{array}$ & $\begin{array}{l}\text { Up to } 3 \text { credits are awarded where concrete used in the } \\
\text { building construction or refurbishment has a significant } \\
\text { recycled content: } \\
\text { - } 1 \text { credit is awarded for aggregate replacement in } \\
75 \% \text { of all concrete by volume as follows: } 1 \text { credit = } \\
30 \% \text { of aggregate is recycled concrete aggregate (or } \\
\text { equivalent). } \\
\text { Up to } 2 \text { credits for awarded for use of supplementary } \\
\text { cementitious materials in } 75 \% \text { of all concrete by } \\
\text { volume as follows: } 1 \text { credit = } 30 \% \text { of cement is } \\
\text { replaced with industrial waste product; } 2 \text { credits = } 60 \% \\
\text { of cement is replaced with industrial waste product } \\
\text { (for precast concrete the } \% \text { of cement replacement is } \\
\text { reduced to } 20 \% \text { for } 1 \text { credit and } 40 \% \text { for } 2 \text { credits). } \\
\text { If no new concrete is used in the refurbishment of an } \\
\text { existing building type "n/a" in the credits achieved column. }\end{array}$ & 3 \\
\hline
\end{tabular}

Table 3: Green Star - Offie Design (v1) Credits regarding Concrete (Green Building Council Australia, 2004)

The challenge for the $\mathrm{CH}_{2}$ team was that while the pioneer building $60 \mathrm{~L}$ (60 Leicester Street, Melbourne) had achieved up to $60 \%$ replacement of OPC with supplementaries, this had been achieved in concrete in a low-rise project. Furthermore the Green Star credit for pre-cast concrete was a target that was theoretically achievable - but untested in the field.

$\mathrm{CH}_{2}$ on the other hand presented a number of challenges:

- The building stands 11 storeys high and requires high-strength floor slabs and columns developing up to $80 \mathrm{MPa}$.

- $32 \%$ of the total quantity of concrete used is precast, including many curved concrete ceiling panels requiring a very high class of visual finish.

- The project was driven by tight commercial realities, i.e. there was little provision to delay stripping of concrete to allow the use of later strength-developing high-extender mixes. This would also prove a challenge with regard to managing shrinkage and cracking.
$\mathrm{CH}_{2}$ was keen to achieve three credits in this area. A strategy therefore needed to be developed to measure and document that credits were being met. This strategy, which evolved through tender and post-tender discussions between the builder, Melbourne City Council and the architects, took the following form:

i) Develop a complete matrix of concrete elements to be used in the project which addressed for each element the $\%$ of total concrete, the number of days at which requisite strength would be developed, and so forth (refer Table $4 \mathrm{a}$ and $4 \mathrm{~b}$ )

ii) Dynamically identify stretch targets and problem areas in the pre- construction stage

iii) Undertake in-depth builder-architect workshops to establish what may be possible

iv) Testing, research and development by concrete contractors to establish parameters

\begin{tabular}{|l|c|c|c|c|c|c|c|c|c|c|c|}
\hline Element & $\begin{array}{c}\text { Mix } \\
\text { designation }\end{array}$ & $\begin{array}{c}\text { Comment } \\
\text { risk }\end{array}$ & Strength & $\begin{array}{c}\text { Drying } \\
\text { shrinkage }\end{array}$ & $\begin{array}{c}\text { Opportunities } \\
\text { for reduction }\end{array}$ & $\begin{array}{c}\text { Cenement } \\
\text { replacement } \\
\%\end{array}$ & $\begin{array}{c}\text { Aggregate } \\
\text { replacement } \\
\%\end{array}$ & slump & plasticer & qty & supplier \\
\hline & & & & & & & & & & \\
\hline
\end{tabular}

Table 4a: Summary of input to concrete matrix (for full version see www.ch2.com.au)

\begin{tabular}{|l|l|l|l|l|l|l|l|}
\hline \multicolumn{2}{|l|}{} & Qty m3 & $\begin{array}{l}\text { \% of concrete } \\
\text { on job }\end{array}$ & Aggregate repl & $\begin{array}{l}\text { \% of project cenent } \\
\text { repl }\end{array}$ & Cement mat repl & $\%$ of proj agg repl \\
\hline & & & & & & \\
\hline
\end{tabular}

Table 4b: Outcome of concrete matrix 
One early outcome of this process was an application by Boral to the Green Building Council for an exemption to enable washed aggregate (aggregate washed out of unused concrete returned from $\mathrm{CH}_{2}$ or other projects) to qualify as 'recycled' aggregate under the credit. This exemption was granted. Even though the amount of this aggregate only account for $1-2 \%$ of the aggregate used in the project it proved crucial in assisting the project reach the levels set.

Boral undertook to achieve the targets identified in the matrix - but this was new territory for the company. Boral had a unique commercial advantage in the project as three of its city plants had facilities to crush recycled concrete - critical to the project reaching recycled aggregate targets. Boral was unwilling to use genuine post-consumer recycled aggregate (such as that available from their venture partner Delta or Alex Fraser) in most high-strength applications due to concerns about the effects of residual cement on binding strength, shrinkage and other technical performance characteristics

The process threw up a number of subtleties that were not reflected in the Green Star credits. Not least of these were that the supplementaries locally available in each state in Australia have quite different performance characteristics.

One very positive outcome of the project was an agreement reached with Boral to share some aspects of the concrete's characteristics in the public domain. This data was forwarded to the Green Building Council to assist with the refinement of the rating tools.

\section{Construction was not without its challenges:}

- Significant cracking was encountered with one major floor slab. While this was found not to affect structural integrity or aesthetics (it was hidden under the access floor) it required further refinement by Boral to address the problem.

- The physical characteristics of the mix resulted in different flow patterns and mix behaviour in pouring the curved precast concrete panels including scalloping, bubbling and colour variation - all highly problematic in this high visibility feature. This was only resolved through significant experimentation and development, costs for which were born by the client.

\section{Environmental benefits of concrete specification}

Detailed analysis of the embodied energy savings achieved at $\mathrm{CH}_{2}$ have not been undertaken. Without this it is difficult to establish the levels of savings made, particularly as there are indications that in some instances concrete contractors increased the total quantity of OPC in the mix to achieve strength and performance, in addition to requisite levels of supplementaries. However, it is possible that significant savings have been achieved - in addition to contributing significantly to the state of knowledge as to what is possible. It is not unlikely that the project has saved between 20 and $30 \%$ of potential embodied energy (worked out from the concrete schedule and percentages saved).

\section{ENVIRONMENTAL BENEFITS}

There is no doubt that the exhaustive specification process has reduced the environmental burden associated with the construction of $\mathrm{CH}_{2}$. The example of concrete alone indicates a significant greenhouse gas saving. Other key examples of likely benefits include:
- Avoided use of rainforest and high-conservation value forests for much of the timber construction through use of recycled timbers.

- Reduction in embodied energy from use of $100 \%$ post-consumer recycled content steel for reinforcement.

- Design for reduced materials use, flexibility and demountability in the fitout. As well as savings in capital construction this is likely to result in compound savings through avoided consumption and waste during churn.

- Savings for the project-wide emphasis on specification for the 100 year life-cycle costing model, with its emphasis on durability.

Accurate quantification of the environmental savings and avoided impacts will only be possible when an audit has been undertaken. This will hopefully be the subject of future research.

\section{Supply chain transformation}

$\mathrm{CH}_{2}$ has already had dramatic effects on the broader building materials supply chain through its iconic status, profile, and significance as a public sector building breaking new ground which is likely to a greater or lesser extent to be pursued by other projects. Examples of this include:

- The development of new products specifically for the project, e.g. the shower towers, precast and in-situ concrete mixes.

- Placing pressure on a broad web of manufacturers and suppliers to think about and gather data on the environmental performance and characteristics of their products.

\section{Contract development}

A key area of concern and barrier for many projects breaking new ground is how to manage risk. There are a number of areas in which $\mathrm{CH}_{2}$ has re-thought contractual arrangements to allocate, share or manage new risks with regard to materials. These include:

- Development of the EPQ-approved approach and, potentially, a specific bank guarantee to minimize risks of undesirable product substitution on-site.

Illustration of challenges, complexities and barriers

Like any innovation, one of the greatest contributions by $\mathrm{CH}_{2}$ to ESD will no doubt be identification of challenges, complexities and barriers arising. Some of these are already clear, but others may well arise in time. They include:

- The challenge of maintaining quality control in areas of new product development (refer Appendix 1).

- Identifying environmentally preferable products. Regardless of the complexity of product assessment processes, no team has access to perfect information. The use of Ecoselect and subsequent concerns of environment groups illustrated the challenges of design teams and their consultants being sustainability experts across a literal planetary range of products.

- Negotiating solutions to unforeseeable situations arising from the use of novel materials with contractual parties in the framework of traditionally adversarial and risk-averse contractual relationships. 
Explicit diffusion, communication and education

Melbourne City Council has embarked on a comprehensive knowledge diffusion program. Lectures, seminars, conferences, books, articles in trade press and the broader media have all contributed to lifting awareness of the project, its ESD ambitions, and what it set out to achieve. As the project moves to completion the emphasis will turn to articles in the architectural magazines that designers and clients read. $\mathrm{CH}_{2}$ will be further researched and written up in case studies. This broad communication agenda ensures that many of the lessons and achievements of $\mathrm{CH}_{2}$ will be taken up by other projects. The benefits will thus multiply.

While the extensive database of 'scored' products remains the intellectual property of Designlnc, Melbourne City Council is exploring ways to make at least some of this knowledge available to a broader audience. In the meantime this knowledge provides an important resource that will enable the architects to leverage off the experience of $\mathrm{CH}_{2}$ to pursue eco-preferable products in other projects, public and private sector, and set a benchmark for other firms to meet and surpass.

Participation in the development of $\mathrm{CH}_{2}$ has stretched and educated all involved. One outcome of the project will be a more educated cadre of architects, engineering and cost-planning consultants, builders and sub-contractors.

\section{Achievements and challenges}

Perhaps as significant as the 'iconic' achievements of $\mathrm{CH}_{2}$ are the many small changes in approach, many of which will probably never be documented. One example of this Bertoni has noticed have been attitudes to waste on site:

Once you start seriously dealing with ESD design it is not just quality and aesthetics driven on conventional lines. I don't think we have wasted anything, we have repaired it instead. If a precast slab turns up that is not quite right we don't send it back. It represents a significant resource and energy investment. Instead we ask how we can resolve an apparent problem. ${ }^{6}$

This raises some real challenges to the architect or project supervisor. Building contracts and Australian Standards have evolved over time to allow tight control over the quality, cost and extent of projects: but what happens where there is no contractual experience or Australian Standard? The use of high-supplementary mix concretes on $\mathrm{CH}_{2}$ is a case in point. The reality, as discussed in the case study, has been finishes that are not classified under and do not meet any standard.

How does the architect hold the builder to account? How does the supervisor prevent a drop in perceived quality? The only answer to this appears to be more hands-on time, in the concrete yard, in the joinery shop, as indeed things were 20 years ago. As Bertoni says; "ESD has generated a new generation of products which are simply not well understood. There is a learning curve for what they can and can't do, and the project simply has to allow more time upfront with the builder to make sure things are done right." 7

\section{CONCLUSION}

Green building is at the point in which there is still a lot of learning for all involved. Each new project contributes to the knowledge of those working on it as well as bringing benefits to the environment and community. This demonstrates the continued requirements of education of architects, the construction industry and the product manufacturing industry. This paper has demonstrated the challenges and opportunities of integrating environmentally responsible materials into a building project. Opportunities lie in selecting materials that have not only a low impact in their manufacture and use but also within their aesthetics and inherent qualities (strength, recyclability, etc.) have longevity.

\section{REFERENCES}

AGO (1999), Australian Residential Building Sector Greenhouse Gas Emissions 1990-2010, Australian Greenhouse Office, Canberra.

Anderson, J., Shiers, D. and Sinclair, M. (2002), The Green Guide to Housing Specification, 3rd, edition, Blackwell Science, Oxford.

Berge, B. (2001), Ecology of Building Materials, Architectural Press, Oxford.

Cole, R.J. (1998), 'Energy and Greenhouse Gas Emissions Associated with the Construction of Alternative Structural Systems', Building and Environment, vol.34, no.3, pp.335-48.

Cole, R.J. and Kernan, P.C. (1996), 'Life-cycle Energy Use in Office Buildings', Building and Environment, vol.31, no.4, pp.30717.

Curwell, S. (2002), Hazardous Building Materials: A Guide to the Selection of Environmentally Responsible, E\&FN Spon Press, London.

Global Green USA (no date), Green Building Materials: Selection and specification guide.

Green Building Council Australia (2004), Green Star - Office Design v.1, Green Building Council Australia, Sydney, viewed 11/01/2005 <http://www.gbcaus.org/>

Greening the Building Life Cycle (2000), Life Cycle Assessment Tools in Building and Construction, Case studies: Embodied Energy (input/output) Analysis of a Range of Building Designs, Commercial case studies: Small Office 1 and 2, Environment Australia, viewed 23/02/2005 <http://buildlca.rmit.edu.au/menu9. html>.

OECD (2002), Design of Sustainable Building Policies: Scope for Improvement and Barriers, OECD, Paris

OECD (2003), Environmentally Sustainable Buildings: Challenges and Policies, OECD, Paris.

Pears, A. (2000), 'Pitfalls in Consideration of Energy in Lifecycle Analysis', in proceedings of the Second National Conference on Lifecycle Assessment: Pathways to Eco Efficiency, 23 to 24th February 2000, VUT Conference Centre Melbourne, viewed 23/02/2005 <http://lca-conf.rmit.edu.au/Papers.html >.

Roodman, D.M. and Lenssen, N. (1995), A Building Revolution: How Ecology and Health Concerns are Transforming Construction, Worldwatch Institute, Washington, DC.

\footnotetext{
${ }^{6}$ Conversation with Claude Bertoni 24/01/2005

Ibid.
} 
Scheuer, C., Keoleian, G.A. and Reppe, P. (2003), 'Life Cycle

Energy and Environmental Performance of a New University

Building: Modelling Challenges and Design Implications', Energy and Buildings, vol.35, no.10, pp.1049-64.

Suzuki, M. and Oka, T. (1998), 'Estimation of Life Cycle Energy Consumption and $\mathrm{CO}_{2}$ Emission of Office Buildings in Japan',

Energy and Buildings, vol.28, no.1, pp.33-41.

US Environmental Protection Agency (2004), Environmentally Preferable Purchasing Terms, US Environmental Protection Agency, Viewed 31/01/2005 < http://www.epa.gov/epp/about/ eppterms.htm\#terms-e >

Woolley, T. and Kimmins, S. (2000), Green Building Handbook Vol II: A Guide to Building Products and their Impact on the Environment, E\&FN Spon, London. 
1. Be careful of greenwash.

2. There is no avoiding research - allow for time and resources to enable good decision making:

- use existing tools e.g. EcoSpecifier, the Environment Design Guide, case studies, internet.

- use contacts.

- attend conferences to keep up to date.

- develop an in-house assessment system/checklist - check out the one page materials questionnaire on EcoSpecifier as an example.

- be patient with and communicate clearly with suppliers.

- work towards developing an in-house materials database and staff education strategies to learn from the process.

3. Bring materials to the front of the design process.

4. Rethink preconceived notions of material selection and application.

5. Design in solutions that minimize material consumption, e.g. maximize natural/integrated (not applied) finishes, therefore materials to be a natural backdrop to form, not a primary aesthetic.

6. Understand what you are specifying so you don't get caught out later:

- cost and time implications - be prepared that some items may cost more due to availability, but demand will eventually bring prices down.

- suitability of the product for the intended application.

7. Collaborate with local environmental groups - they can be a good source of information.

8. Be more amenable to variations in visual finish control to minimize material wastage through rejection:

- develop a good relationship/commentary with the builder to ensure project objectives and quality are delivered.

- where options exist, choose a process that gives a good result with the least risk of material wastage.

- where a more refined finish is required, limit it to smaller areas.

9. Be realistic about life span design considerations e.g. if the design aims at flexibility or is faddish, then demountability, recyclability and reuse may be more important than long term durability.

10. Don't get lost in the enormity of the exercise - take it in small bites and don't feel the need to reinvent the wheel every time. Making a small improvement is better than none at all. 